\title{
ARTERIAL HYPERTENSION IN CHRONIC RENAL DISEASE
}

\author{
Merita Alimadhi ${ }^{1}$, Nestor Thereska ${ }^{2}$ \\ ${ }^{I}$ Regional Hospital of Fier, Albania; \\ ${ }^{2}$ University Hospital Centre "Mother Teresa", Tirana, Albania;
}

Corresponding author: Merita Alimadhi, Email: meritaalimadhi@ yahoo.com;

Received September, 2018; Accepted September, 2018; Published October, 2018;

DOI: https://doi.org/10.31407/ijees8429

UOI license: http://u-o-i.org/1.01/ijees/39813821

\begin{abstract}
Hypertension is both an important cause and consequence of chronic kidney disease. Evidence from numerous clinical trials has demonstrated the benefit of blood pressure control. However, it remains unclear whether available results could be extrapolated to patients with chronic kidney diseases because most studies on hypertension have excluded patients with kidney failure. In addition, chronic kidney disease encompasses a large group of clinical disorders with heterogeneous natural history and pathogenesis. In this paper, we review current evidence supporting treatment of hypertension in various forms of chronic kidney disease and highlight some of the gaps in the extant literature.
\end{abstract}

Key words: chronic renal disease, hypertension, treatment, prevention 